\title{
Fermented foods and preterm birth risk from a prospective large cohort study: the Japan Environment and Children's study
}

Mika Ito ${ }^{1}$, Ayako Takamori' ${ }^{2}$, Satoshi Yoneda ${ }^{1}$, Arihiro Shiozaki ${ }^{1}$, Akiko Tsuchida $^{3,4}$, Kenta Matsumura ${ }^{3}$, Kei Hamazaki ${ }^{3,4}$, Noriko Yoneda ${ }^{1}$, Hideki Origasa ${ }^{5}$, Hidekuni Inadera ${ }^{3,4}$, Shigeru Saito ${ }^{1 *}$ (D) and Japan Environment and Children's Study (JECS) Group

\begin{abstract}
Background: The dietary pattern of pregnant women is known to be associated with preterm birth (PTB). We investigated whether PTB was associated with intake of fermented food by using data from the Japan Environment and Children's Study.

Methods: From a data set of 103,099 pregnancies, 77,667 cases at low risk for PTB were analyzed. The primary outcome measurements were based on PTB. Fermented food (miso soup, yogurt, cheese, and fermented soybeans) consumption was assessed by using a semi-quantitative food frequency questionnaire.

Results: Intake of miso soup, yogurt, and fermented soybeans before pregnancy significantly reduced the risk of early PTB (<34 weeks). The adjusted odds ratio (OR) for early PTB in women who had miso soup 1-2 days/week, 3-4 days/ week, or $\geq 5$ days/week were $0.58,0.69$, and 0.62 , respectively, compared with those who had miso soup $<1$ day/week (95\% confidence interval (Cl) 0.40-0.85, 0.49-0.98, and 0.44-0.87). The adjusted OR for early PTB in women who ate yogurt $\geq 3$ times/week was 0.62 ( $95 \% \mathrm{Cl}, 0.44-0.87$ ) compared to those who ate yogurt $<1$ time/week. The adjusted OR for early PTB in women who ate fermented soybeans $\geq 3$ times/week was 0.60 ( $95 \% \mathrm{Cl}, 0.43-0.84)$ compared to those who ate $<1$ time/week. However, the incidence of overall PTB and late PTB (34-36 weeks) was not associated with fermented food intake.
\end{abstract}

Conclusion: PTB low-risk women with a high consumption of miso soup, yogurt, and fermented soybeans before pregnancy have a reduced risk of early PTB.

Keywords: Preterm delivery, Miso, Yogurt, Cheese, Fermented soybeans, Natto, The Japan environment and Children's study, JECS

\section{Background}

Preterm birth (PTB) is the most significant adverse outcome for maternal and child health in many countries [1-3]. Premature infants are also likely to have long-term impairment and social inequality in their adult life [4] .

There is evidence supporting an association between the dietary pattern of pregnant women and PTB. The Norwegian Mother and Child Cohort Study $(n=66,000$ women) revealed that a "prudent" dietary pattern, such

\footnotetext{
* Correspondence: s30saito@med.u-toyama.ac.jp

'Department of Obstetrics and Gynecology, Faculty of Medicine, University

of Toyama, 2630 Sugitani, Toyama City, Toyama 930-0194, Japan

Full list of author information is available at the end of the article
}

as higher intake of vegetables, fruits, oils, water, and whole-grain cereals, or a "traditional" dietary pattern, such as potatoes and fish, was associated with a $12 \%$ and 9\% reduced risk of PTB, respectively [5]. Further, protein-rich and low fat foods were reported to reduce the risk of PTB $[6,7]$. In addition to these, fermented foods such as miso soup, yogurt, cheese, and fermented soybeans effect to reduce the risk of PTB, because entero-bacterial flora in PTB cases was different from that in non-PTB cases [8].

Another cohort study in Norway demonstrated an association between high intake of probiotic dairy products and reduced risk of spontaneous PTB [9]. Especially,

(c) The Author(s). 2019 Open Access This article is distributed under the terms of the Creative Commons Attribution 4.0 International License (http//creativecommons.org/licenses/by/4.0/), which permits unrestricted use, distribution, and reproduction in any medium, provided you give appropriate credit to the original author(s) and the source, provide a link to the Creative Commons license, and indicate if changes were made. The Creative Commons Public Domain Dedication waiver (http://creativecommons.org/publicdomain/zero/1.0/) applies to the data made available in this article, unless otherwise stated. 
probiotic intake during the early gestation period was associated with a lower risk of preterm delivery [10]. Kriss et al. reported that the consumption of yogurt by non-obese Mexican women who are classified into low risk of PTB, reduced their risk of PTB [11]. A meta-analysis concluded that probiotic or prebiotic intake during pregnancy did not decrease PTB [12], although the timing and duration of probiotic administration were not consistent across the various studies. A recent study analyzed the difference in outcomes with the timing of probiotic intake and demonstrated that while probiotic intake during early pregnancy reduced PTB, there was no such benefit with intake during late pregnancy PTB [10].

Fermented foods have received attention globally for their role in supporting human health by improving intestinal bacterial flora. Miso is prepared from fermented soybeans. Miso soup, which contains "dashi" stock with miso, is one of the most popular soups in Japan. Fermented soybeans are a traditional Japanese food that have attracted attention for containing protein, isoflavones, and vitamin $\mathrm{K}$. Cheese contains some important nutrients, including calcium and protein, along with vitamin $\mathrm{B}_{12}$ and zinc.

In vitro and in vivo studies have suggested that specific fermentation products may actively participate in establishing proper immunological balance $[13,14]$. Therefore, we examined whether the intake of fermented foods such as miso soup, yogurt, cheese, and fermented soybeans during early pregnancy period reduces PTB.

\section{Methods}

\section{JECS population}

The current study was based on the Japan Environment and Children's Study (JECS) data set of 103,099 pregnancies. The JECS is a nationwide, government-funded, multicenter, prospective birth cohort study conducted by the Ministry of the Environment of Japan; details of the study design have been described previously $[15,16]$, and the characteristics of the project population were reported by Michikawa et al. [16]. The goal of the JECS was to evaluate the effects of different environmental factors on children's health and development. Written informed consent was obtained from all participating women and their partners.

Pregnant women were recruited from 15 areas in Japan between January 2011 and March 2014. The present study was based on the following datasets: "jecs-ag-20,160,424" (released in June, 2016) and "allbirth_revice001_ver001" (released in October, 2016). All data were obtained from self-reported questionnaires and included information obtained during the first trimester (first questionnaire about pre-pregnancy status) and the second or third trimesters (second questionnaire about prenatal status). Prenatal exposure was assessed by using a semi-quantitative food frequency questionnaire (FFQ) that comprised a list of foods with standard portion (bowl) sizes commonly consumed in Japan [17].

A part of the participants who experienced early PTB did not write in the second questionnaire. We mainly analyzed the first questionnaire data in this study because we want to analyze both early (before $34^{+0}$ weeks) PTB and late $\left(34^{+0}\right.$ to $36^{+6}$ weeks) PTB. The four fermented foods that we analyzed in the first questionnaire correlated with those in second questionnaire (see Additional file 1: Table S1). Significant positive correlations for fermented foods such as miso soup, yogurt, cheese, and fermented soybeans were observed between first questionnaire and second questionnaire.

\section{Preterm birth (PTB)}

The primary outcome, PTB, was defined as birth before gestational week $37^{+0}$. Secondary outcomes were studied by subgrouping PTB as late and early, based on medical (clinical) records.

\section{Fermented foods (miso soup, fermented soybeans, etc.)} In order to assess the frequency of miso soup intake, the following questions were included in the self-administered questionnaire: "How many times do you have miso soup?" There were six response options: Less than 1 day/month, 1-3 days/month, 1-2 days/week, 3-4 days/week, 5-6 days/week, or every day. In order to assess the frequency of yogurt, cheese, and fermented soybean intake, the following question was included in the self-administered questionnaire: "How many times do you have yogurt (cheese or fermented soybeans)?" There were nine response options: Less than 1 time/month, 1-3 times/ month, 1-2 times/week, 3-4 times/week, 5-6 times/week, 1 time/day, 2-3 times/day, 4-6 times/day, or $\geq 7$ times/ day.

To estimate the risk of PTB based on the intake of each fermented food, we categorized participant responses for consumption of each food type as follows: miso soup, 1-2 days/week, 3-4 days/week, or $\geq 5$ days/ week and yogurt, < once per week, 1-4 times/week, or $\geq 5$ times/week according to previous research [11]. The consumption of cheese and fermented soybeans was categorized as < once/week, 1-2 times/week, or $\geq 3$ times/ week.

\section{Statistical methods}

Univariate and multivariate logistic analyses were applied to estimate the risk of PTB. We had regarded that two independent PTBs (that is, late PTB and early PTB) existed because they have different risk factors and different profiles. So we did not use multi-nominal logistic regression. We calculated both unadjusted and adjusted odds ratios (OR) with 95\% confidence interval (95\% CI). 
Data were expressed as number of PTB cases (2 groups; yes or no) for each category and proportion (\%). All statistical analyses were performed by using a statistical software JMP statistical package version 12 and SAS version 9.4 (SAS Institute Inc., Cary, NC). All two-sided $p$ values $<0.05$ were considered statistically significant.

\section{Confounding factors for multiple analyses}

The confounding factors for multiple logistic models were recognized as follows: age, categorized into 3 groups $(\geq 35,30-34$, or $<30)$; number of previous deliveries (nulliparous: yes/no); pre-pregnancy body mass index (BMI) $\left(\mathrm{kg} / \mathrm{m}^{2}\right):<18.5,18.5-25$, or $\geq 25$; smoking status $(1=$ never, 2 = previously smoked but quit prior to current pregnancy, 3 = previously smoked but quit after knowledge of current pregnancy, $4=$ currently smoking) for the first trimester (for subsequent trimesters, participants were grouped as smoked or never smoked; educational background (junior high school, high school, technical junior college, technical/vocational college, associate degree, bachelor's degree, or graduate degree such as Masters/Doctors) was categorized as < 10 years, 10-12 years, 13-15 years, or $\geq 16$ years; annual family income (million JPY) was classified as $<2,2-4,4-6,6-8$, or $\geq 10$; working $\geq 42 \mathrm{~h}$ /week calculating from first questionnaire according to previous research [18]: yes/no); and part-timer (yes/no). These confounding factors were reported as risk factors of PTB [2, 19].

The study protocol was reviewed and approved by the Ministry of the Environment's Institutional Review Board on Epidemiological Studies and by the Ethics Committee of all participating institutions.

\section{Results}

\section{Participants}

A total of 103,099 pregnancies were analyzed. Initially, the following groups were excluded: participants who withdrew from the study $(n=29)$, multiple pregnancies $(n=991)$, miscarriage or stillbirth $(n=1537)$, inadequate information about birth $(n=2290)$. Further, based on the responses provided in the follow-up questionnaire, the following participants were excluded: known risk factors for PTB and the cause of artificial PTB (hypertension $[n=1206]$, diabetes $[n=1069]$, heart disease $[n=296]$, renal disease $[n=331]$, autoimmune disease $[n=190]$, cerebral infarction $[n=15]$, cerebral hemorrhage $[n=$ $15]$, epilepsy $[n=248]$, psychiatric disorder $[n=778]$, malignant disease $[n=53]$, maternal death $[n=9])$; steroid use during pregnancy (internal use, inhalation and injection use, $n=1516$ ); pregnancy complications (gestational diabetes mellitus [GDM], $n=2647$ ); placental abruption $(n=398)$; placenta previa $(n=589)$; polyhydramnios $(n=391)$; oligohydramnios $(n=1251)$; fetal disorder $(n=2401)$; severe $(n=936)$ and mild $(n=2231)$ hypertensive disorders of pregnancy; fetal growth restriction [FGR], $n=1969$; fetal anomaly $(n=2834)$; and participants with missing information on miso soup, yogurt, cheese or fermented soybean consumption $(n=1322)$. Finally, the remaining 77,667 participants without a history of preterm delivery were included for analysis (Fig. 1). Furthermore, 2507 participants who had a history of preterm delivery that is a great risk for PTB were included for additional analysis.

\section{Characteristics of the study subjects}

The average age at delivery for the 77,667 women in this study was $30.9 \pm 5.0$ years; mean BMI was $21.1 \pm 3.0 \mathrm{~kg} /$ $\mathrm{m}^{2}$; and mean gestational weeks at delivery was $38.9 \pm$ 1.4 weeks.

The prevalence of PTB in the population was $3.0 \%$ $(2343 / 77,667)$. This prevalence of PTB was lower than in prevalence of PTB in Japan (5.6\%), because we have excluded the high risk populations. Older age, low BMI, multiparity, lower education level, and lower income were the significant risk factors for PTB $(p=<0.001,<$ $0.001,0.022,0.028$, and 0.032 , respectively; Table 1 ). There was not a large correlation coefficient among these foods intake frequencies and between these fermented foods intake and covariates $(r \leq 0.32$, see Additional file 2: Table S2),

\section{The difference of fermented food intake state condition by women's background}

Consumption of miso soup was significantly higher in older people, low BMI individuals, non-smokers, multiparous women, and those with high educational background, high household income, not part-timer, and working $<42 \mathrm{~h} /$ week $(p<0.001, p<0.001, p<0.001, p<$ $0.001, p<0.001, p<0.001, p<0.001$ and $p<0.001$, respectively) (Table 2). Nearly the same results were obtained about consumption of cheese and fermented soybeans. But only yogurt consumption was significantly higher in nulliparous women and working $\geq 42 \mathrm{~h} /$ week $(p<0.001$ and $p<0.001$, respectively, not shown in tables).

\section{Association between overall PTB and consumption of fermented foods}

Table 3 shows the number of cases and the odds ratio (OR) for overall PTB risk as unadjusted and adjusted. Intake of miso soup 1-2 days/week was significantly associated with a lower risk of PTB (unadjusted OR for PTB [95\% confidence interval], 0.86 [0.75-0.98]. However, on multivariate analysis, there were no significant associations between risk of PTB and consumption of yogurt, cheese, or fermented soybeans (Table 3 ). 


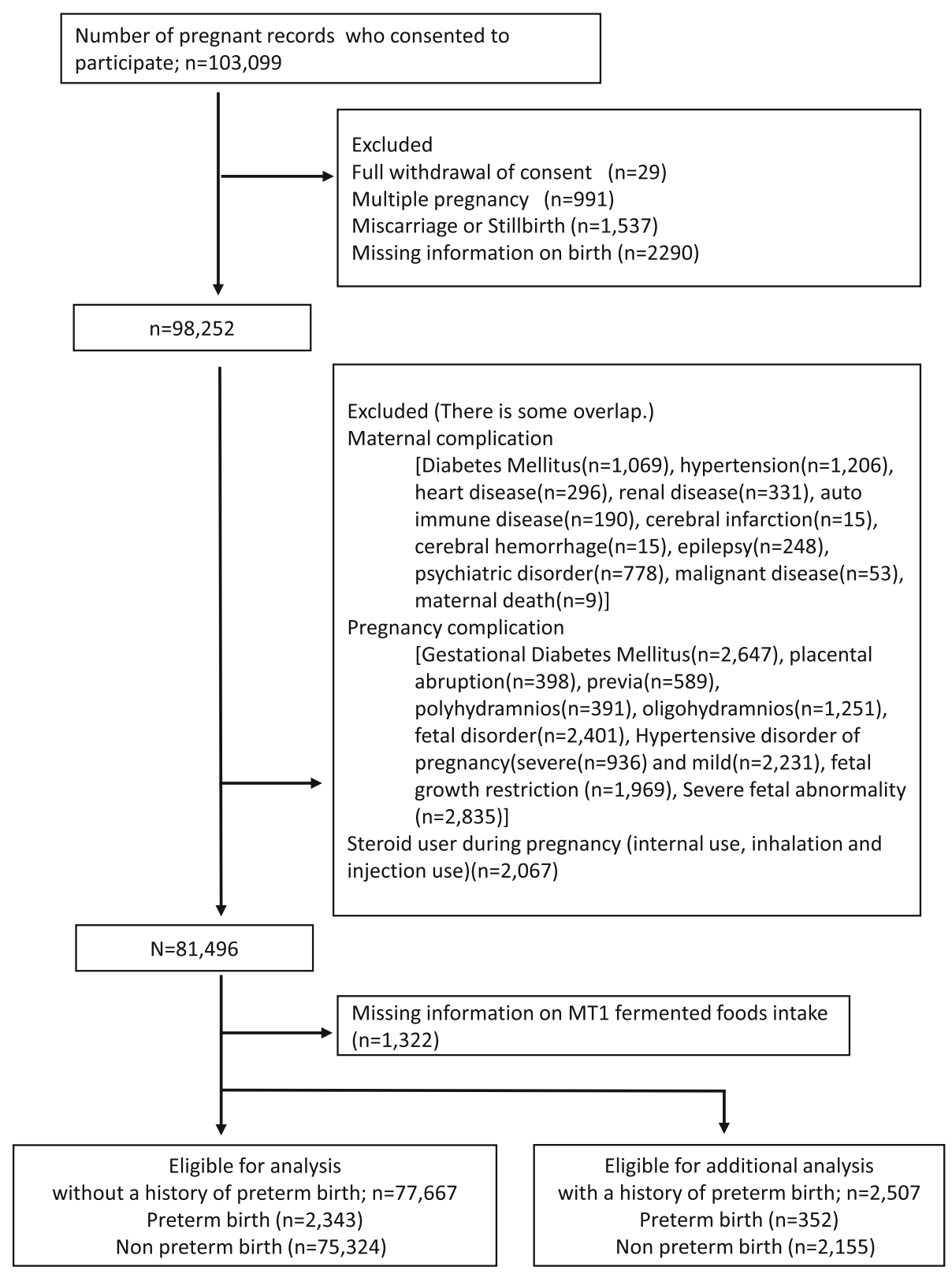

Fig. 1 Flow chart showing selection of study subjects

Early PTB (<34 weeks) or late PTB (34-36 weeks)

Table 4 shows the number of cases and adjusted OR for PTB based on period of gestation. Miso soup intake 1-2 days/week, 3-4 days/week or $\geq 5$ days/week significantly reduced the adjusted OR for early PTB ( $<34$ weeks) (adjusted ORs [95\% CI] were 0.58 [0.40-0.85], 0.70 [0.49-0.99], and 0.62 [0.44-0.88], respectively) (Table $4 \mathrm{~A})$. The adjusted OR for early PTB (<34 weeks) in women who had miso soup $\geq 1$ day/week was 0.63 compared with those who had miso soup < 1 day/week (95\% CI 0.47-0.85; not shown in tables). Yogurt intake $\geq 5$ times/week and fermented soybean intake $\geq 3$ times/week significantly reduced the adjusted OR for early PTB (<34 weeks) (adjusted OR [95\% CI], 0.62 (0.44-0.87) and 0.60 (0.43-0.85), respectively) (Table 4A).

Cheese intake more than 3 times/week reduced the frequency of early PTB ( $<34$ weeks), although this was not statistically significant $(p=0.053)$. No association could be identified between the consumption of fermented food and late PTB (Table 4B).

\section{In women with a history of preterm delivery (additional analysis)}

In women with a history of PTB which is known as a major risk factor of PTB, only fermented soybean intake 
Table 1 Characteristics of confounding factors for preterm birth (PTB) cases

\begin{tabular}{|c|c|c|c|c|c|}
\hline \multirow{3}{*}{ Age, $n(\%)$} & \multirow{2}{*}{\multicolumn{2}{|c|}{$\frac{\text { Preterm delivery }}{(n=2343)}$}} & \multirow{2}{*}{\multicolumn{2}{|c|}{$\frac{\text { Non preterm delivery }}{(n=75,324)}$}} & \multirow{3}{*}{$\begin{array}{l}p \text { value } \\
<0.001\end{array}$} \\
\hline & & & & & \\
\hline & & & & & \\
\hline$<30$ years old & 867 & $(37.0)$ & 29,388 & $(39.0)$ & \\
\hline 30-34 years old & 796 & $(34.0)$ & 26,841 & (35.6) & \\
\hline$\geq 35$ years old & 680 & $(29.0)$ & 19,092 & $(25.4)$ & \\
\hline \multicolumn{3}{|l|}{ BMI(kg/m2) group, $n(\%)$} & & & $<0.001$ \\
\hline Leptosome $(<18.5)$ & 488 & $(20.8)$ & 12,272 & $(16.3)$ & \\
\hline Healthy weight(18.5 to < 25) & 1614 & $(68.9)$ & 56,093 & $(74.5)$ & \\
\hline Obese $(\geq 25)$ & 240 & $(10.3)$ & 6924 & $(9.2)$ & \\
\hline \multicolumn{3}{|l|}{ Smoking history, $n(\%)$} & & & 0.083 \\
\hline Yes & 999 & $(43.1)$ & 30,862 & $(41.3)$ & \\
\hline No & 1321 & $(56.9)$ & 43,931 & $(58.7)$ & \\
\hline \multicolumn{3}{|l|}{ Nulliparity, n (\%) } & & & 0.022 \\
\hline Yes & 1015 & $(43.6)$ & 30,927 & $(41.2)$ & \\
\hline No & 1314 & $(56.4)$ & 44,135 & $(58.8)$ & \\
\hline \multicolumn{3}{|c|}{ Educational background (years), $n(\%)$} & & & 0.028 \\
\hline$<10$ & 132 & $(5.9)$ & 3410 & $(4.6)$ & \\
\hline $10-12$ & 748 & $(33.4)$ & 24,652 & $(33.2)$ & \\
\hline $13-15$ & 883 & $(39.4)$ & 29,886 & $(40.2)$ & \\
\hline$\geq 16$ & 476 & $(21.3)$ & 16,417 & $(22.1)$ & \\
\hline \multicolumn{5}{|c|}{ Household income (million Japanese Yen/year), n (\%) } & 0.032 \\
\hline$<2$ & 139 & $(6.6)$ & 3769 & $(5.4)$ & \\
\hline 2 to $<4$ & 706 & $(33.7)$ & 24,147 & $(34.8)$ & \\
\hline 4 to $<6$ & 728 & $(34.7)$ & 22,976 & $(33.1)$ & \\
\hline 6 to $<8$ & 303 & $(14.5)$ & 11,068 & $(15.9)$ & \\
\hline 8 to $<10$ & 125 & $(6.0)$ & 4577 & (6.6) & \\
\hline$\geq 10$ & 95 & $(4.4)$ & 2947 & $(4.2)$ & \\
\hline \multicolumn{3}{|l|}{ Working $>42$ h/week, n (\%) } & & & 0.691 \\
\hline Yes & 481 & $(20.5)$ & 15,211 & $(20.2)$ & \\
\hline No & 1862 & $(79.5)$ & 60,113 & $(79.8)$ & \\
\hline \multicolumn{3}{|l|}{ Part-timer, $n(\%)$} & & & 0.863 \\
\hline Yes & 371 & $(15.8)$ & 12,027 & $(16.0)$ & \\
\hline No & 1972 & $(84.2)$ & 63,297 & $(84.0)$ & \\
\hline
\end{tabular}

Note: BMI; body mass index before pregnancy

1-2 times a week significantly reduced the adjusted OR for early PTB which was $0.52(0.26-0.97)$ (Table 5$)$. Miso soup and yogurt intake did not reduce the risk of early PTB.

\section{Discussion}

In this study, we examined the relationship between PTB and the consumption frequency of fermented food (miso soup, yogurt, cheese, and fermented soybeans) in Japanese pregnant women determined to be at a low risk for PTB by the JECS. The overall risk of PTB was not reduced in women who consumed fermented foods. However, the risk of early PTB ( $<34$ weeks) was reduced in women who consumed miso soup at least 1 day/week, yogurt 5 or more times per week, and fermented soybeans 3 or more times per week. Fermented food consumption did not reduce the frequency of late PTB (34-36 weeks) in this study.

In Japan, two birth-cohorts have been conducted before JECS [21, 22], but both studies are locally limited. The study design of JECS is 100,000 participants from 15 regions of Japan reflecting the whole of the Japanese 
Table 2 Frequency of miso soup intake and characteristics of confounding factors

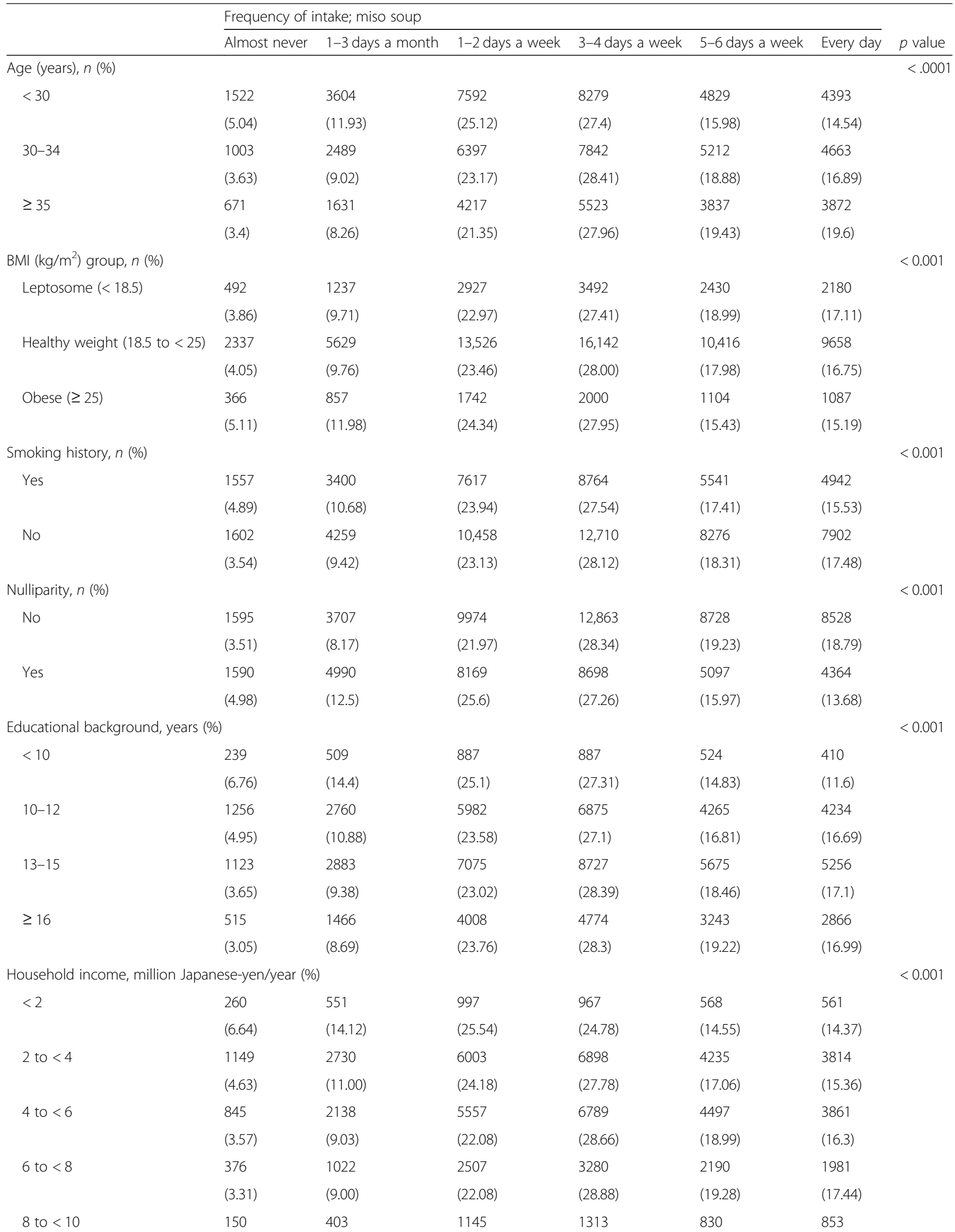


Table 2 Frequency of miso soup intake and characteristics of confounding factors (Continued)

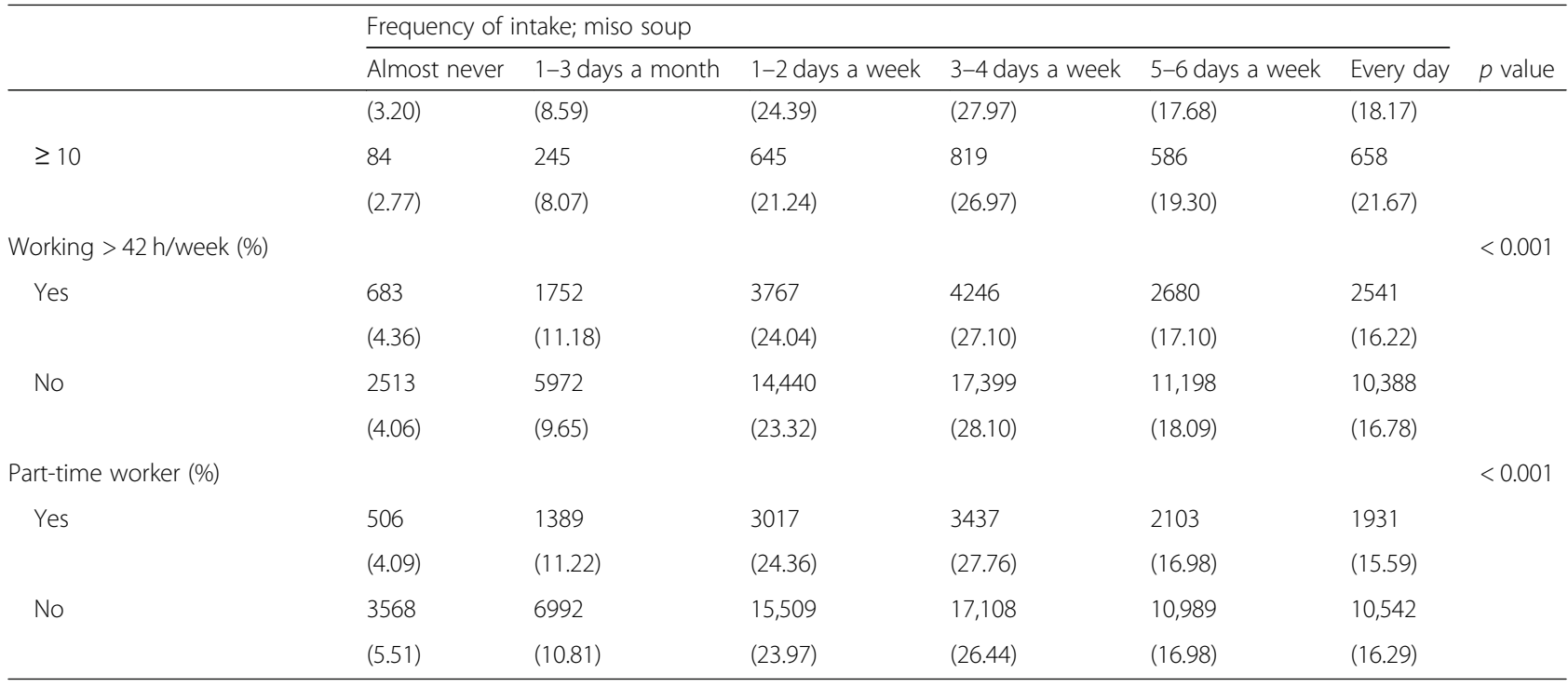

Note: $B M I$ body mass index before pregnancy

pregnant women more accurately. In these former local studies from Japan, they have assessed the dietary habits of pregnant women, but they did not compare PTB risk with food intake. This study is the first report to show the relationship between PTB risk and food intake frequently from Japan.

Fermented food affects the bacterial flora in the intestines and influences mucosal immunity [14] by increasing secretory type IgA [23] and by inducing anti-inflammatory cells [24] such as regulatory T cells [25]. Yogurt, miso, and fermented soybeans are known to have probiotic effects $[26,27]$. Further, the major cause of early PTB $(<34$ weeks) is thought to be intrauterine infection caused by ascending vaginal infection. On the other hand, the risk factors for late PTB are mainly environmental and physical factors such as low BMI [28] and part-time work [20],

Table 3 Odds ratios (OR) for relationships between preterm birth (PTB) risk and fermented food intake frequency before pregnancy by using logistic regression analysis, Japan Environment and Children's birth-cohort Study (JECS)

\begin{tabular}{|c|c|c|c|c|c|}
\hline & Cases/all (\%) & Unadjusted OR (95\% Cl) & $p$ value & Adjusted OR (95\% Cl) & $p$ value \\
\hline \multicolumn{6}{|l|}{ Miso soup, $n(\%)$} \\
\hline$\leq 1$ day a week & $367 / 11,008$ (3.33) & Reference & & Reference & \\
\hline 1-2 days a week & $522 / 18,207(2.87)$ & $0.86(0.75-0.98)$ & 0.025 & $0.87(0.75-1.00)$ & 0.053 \\
\hline 3-4 days a week & $643 / 21,645(2.97)$ & $0.89(0.78-1.01)$ & 0.073 & $0.92(0.80-1.06)$ & 0.228 \\
\hline$\geq 5$ days a week & $811 / 26,807$ (3.03) & $0.91(0.80-1.03)$ & 0.117 & $0.93(0.81-1.06)$ & 0.285 \\
\hline \multicolumn{6}{|l|}{ Yogurt, $n(\%)$} \\
\hline$<1$ time a week & $785 / 25,354(3.10)$ & Reference & & Reference & \\
\hline 1-4 times a week & $1010 / 33,129(3.05)$ & $0.98(0.90-1.08)$ & 0.742 & $0.98(0.89-1.09)$ & 0.735 \\
\hline$\geq 5$ times a week & $548 / 19,184(2.86)$ & $0.92(0.82-1.03)$ & 0.142 & $0.92(0.82-1.04)$ & 0.173 \\
\hline \multicolumn{6}{|l|}{ Cheese, $n$ (\%) } \\
\hline$<1$ time a week & $1132 / 37,567(3.01)$ & Reference & & Reference & \\
\hline 1-2 times a week & 737/23,861 (3.09) & $1.03(0.93-1.13)$ & 0.596 & $1.05(0.95-1.16)$ & 0.353 \\
\hline$\geq 3$ times a week & $474 / 16,239(2.92)$ & $0.97(0.89-1.08)$ & 0.555 & $0.98(0.87-1.10)$ & 0.691 \\
\hline \multicolumn{6}{|c|}{ Fermented soybeans, $n(\%)$} \\
\hline$<1$ time a week & $955 / 30,609$ (3.12) & Reference & & Reference & \\
\hline 1-2 times a week & $813 / 27,474(2.96)$ & $0.95(0.86-1.04)$ & 0.260 & $0.96(0.87-1.06)$ & 0.443 \\
\hline$\geq 3$ times a week & $575 / 19,584(2.94)$ & $0.94(0.85-1.04)$ & 0.242 & $0.96(0.86-1.08)$ & 0.525 \\
\hline
\end{tabular}


Table 4 Odds ratios (ORs) for relationships between PTB risk and fermented food intake frequency before pregnancy by logistic regression analysis, (A)less than 34 weeks, (B) $34+0$ to $36+6$ weeks

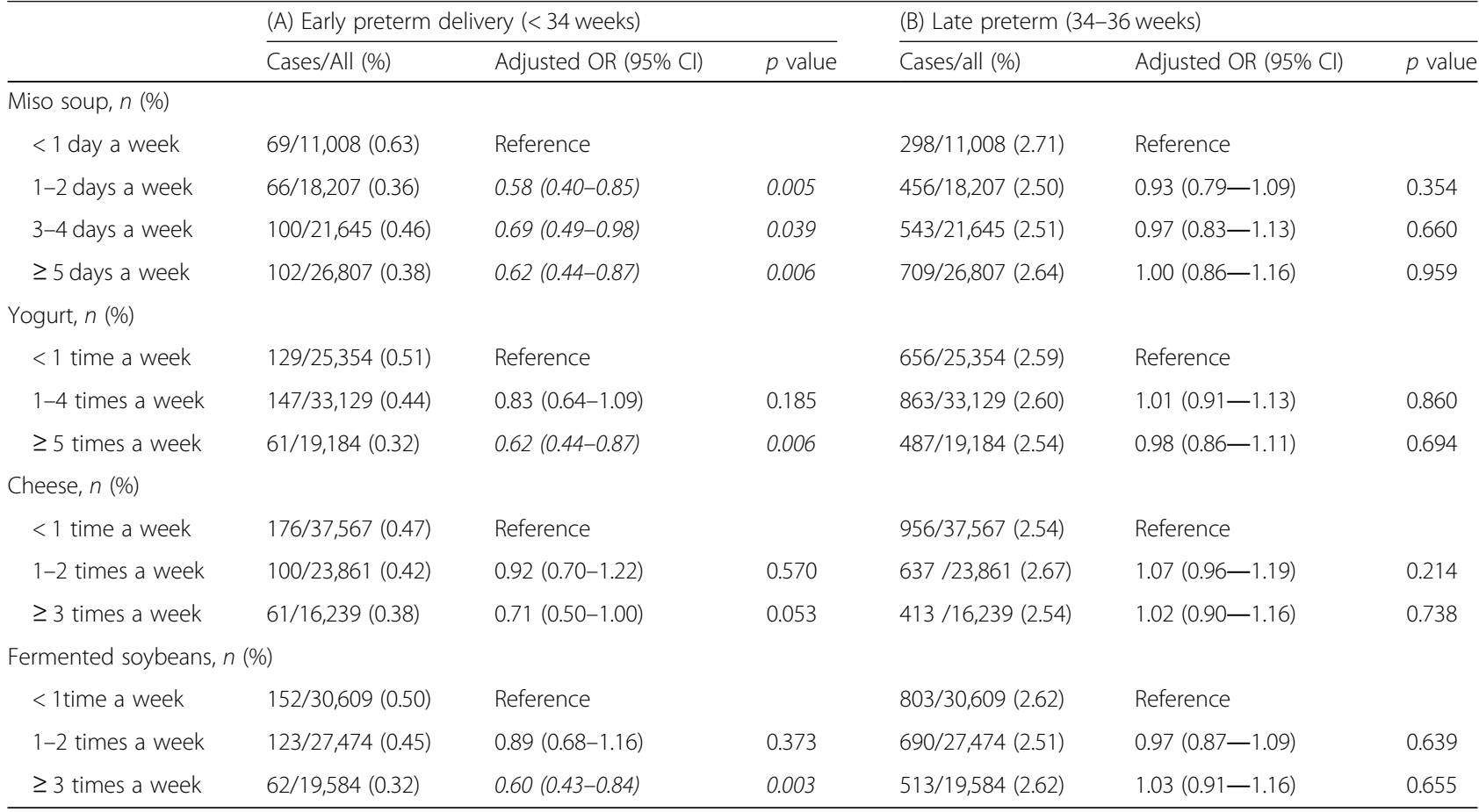

Note: Adjusted OR was estimated by applying multivariable analyses considering the following confounders; (A) mother age, BMI, smoking history, parity, previous, educational background, household income, and working $\geq 42 \mathrm{~h} /$ week, (B) mother age, BMI, smoking history, parity, previous, educational background, household income, and working $\geq 42 \mathrm{~h} /$ week and part-timer. Their categories were shown in the "Methods" section

Table 5 ORs for relationships between PTB risk and fermented food intake frequency before pregnancy in women who have a history of PTB by logistic regression analysis, (A) less than 34 weeks, (B) $34^{+0}$ to $36^{+6}$ weeks (Additional analysis)

\begin{tabular}{|c|c|c|c|c|c|c|}
\hline & \multicolumn{3}{|c|}{ (A) Early preterm delivery (<34 weeks) } & \multicolumn{3}{|c|}{ (B) Late preterm (34-36 weeks) } \\
\hline & Cases/All (\%) & Adjusted OR $(95 \% \mathrm{Cl})$ & $p$ value & Cases/All (\%) & Adjusted OR (95\% Cl) & $p$ value \\
\hline \multicolumn{7}{|l|}{ Miso soup, $n(\%)$} \\
\hline$<1$ day a week & $7 / 311(2.25)$ & Reference & & $32 / 311(10.3)$ & Reference & \\
\hline $1-2$ days a week & $14 / 534(2.62)$ & $0.99(0.38-2.62)$ & 0.991 & 62/534 (11.6) & $1.18(0.74-1.91)$ & 0.481 \\
\hline 3-4 days a week & 26/725 (3.59) & $1.41(0.59-3.39)$ & 0.441 & $80 / 725(11.0)$ & $1.08(0.68-1.71)$ & 0.758 \\
\hline$\geq 5$ days a week & 26/937 (2.77) & $1.17(0.49-2.82)$ & 0.721 & 105/937 (11.2) & $1.03(0.66-1.61)$ & 0.897 \\
\hline \multicolumn{7}{|l|}{ Yogurt, $n(\%)$} \\
\hline$<1$ time a week & 28/844 (3.32) & Reference & & 87/844 (10.3) & Reference & \\
\hline 1-4 times a week & $33 / 1097(3.01)$ & $0.89(0.50-1.57)$ & 0.678 & $132 / 1097(12.0)$ & $1.26(0.92-1.73)$ & 0.146 \\
\hline$\geq 5$ times a week & $12 / 566(2.12)$ & $0.65(0.30-1.38)$ & 0.261 & $60 / 566(10.6)$ & $1.08(0.74-1.57)$ & 0.692 \\
\hline \multicolumn{7}{|l|}{ Cheese, $n(\%)$} \\
\hline$<1$ time a week & $33 / 1161(2.84)$ & Reference & & $122 / 1161(10.5)$ & Reference & \\
\hline 1-2 times a week & 26/782 (3.32) & $1.40(0.79-2.49)$ & 0.247 & $99 / 782(12.7)$ & $1.33(0.98-1.80)$ & 0.065 \\
\hline$\geq 3$ times a week & $14 / 564(2.48)$ & $0.86(0.42-1.78)$ & 0.686 & $58 / 564(10.3)$ & $0.99(0.70-1.41)$ & 0.962 \\
\hline \multicolumn{7}{|c|}{ Fermented soybeans, $n(\%)$} \\
\hline$<1$ time a week & 36/965 (3.73) & Reference & & 104/965 (10.8) & Reference & \\
\hline 1-2 times a week & $21 / 858(2.45)$ & $0.52(0.28-0.97)$ & 0.039 & $95 / 858(11.1)$ & $1.03(0.75-1.41)$ & 0.863 \\
\hline$\geq 3$ times a week & $16 / 684(2.34)$ & $0.52(0.26-1.02)$ & 0.056 & $80 / 684(11.7)$ & $1.03(0.74-1.44)$ & 0.859 \\
\hline
\end{tabular}

Note: Adjusted OR was estimated by applying multivariable analyses considering the following confounders;(A) mother age, BMI, smoking history, parity, previous, educational background, household income and working $\geq 42 \mathrm{~h}$ /week, (B) mother age, BMl, smoking history, parity, previous, educational background, household income and working $\geq 42 \mathrm{~h} /$ week and part-timer. Their categories were shown in method section 
suggesting that the pathogenesis of early and late PTB are different. Therefore, we hypothesized that high consumption of fermented foods may improve immune defenses against infections and reduce the risk of early PTB by improving intestinal bacterial flora.

Several studies have reported on the relationship between PTB and dietary intake. In 2007, the Cochrane Database demonstrated that the use of probiotics effectively reduced bacterial vaginosis during pregnancy [29]. A Mexican group reported that non-overweight women who ate more than 5 cups of yogurt per week had a reduced risk of PTB [11]. In our study, consumption of yogurt $>5$ times/week before pregnancy was found to be associated with a reduced risk of early PTB $(<34$ weeks) but not overall PTB or late PTB. In contrast, probiotic intake during early pregnancy (not before pregnancy) was associated with a lower risk of PTB, especially late PTB, in a Norwegian cohort [10]. In our study, fermented foods after pregnancy did not reduce late PTB, only cheese intake reduced early PTB risk but miso soup, yogurt, or fermented soybeans did not (Additional file 3: Table S3). These discrepancies may be attributed to differences in the micro-organism content of the fermented food or differences in the bacterial flora or genetic background.

Recent reports suggest that younger Japanese are consuming lesser miso [30]. In JECS study, consumption of miso soup was significantly lower in younger people (Table 2). These changes in eating habits may potentially increase the incidence of PTB. Our result means that health guidance for young women before pregnancy about their eating habits may be effective to prevent PTB.

The beneficial effects of probiotics include symptom alleviation for intestinal diseases (e.g., inflammatory bowel disease [31] and Clostridium difficile colitis [32]) and systemic immune diseases (e.g., atopic dermatitis [33], type 2 diabetes [34]), and prophylaxis for acute upper respiratory tract infections [35]. These effects of probiotics on infectious and inflammatory diseases support our hypothesis.

In our study, the distinct effect of fermented food could not be confirmed in women who were at high risk for PTB (Table 5), since the powers of fermented foods are not so effective in high risk women for PTB. The meta-analysis concluded that probiotics during pregnancy have no effect for PTB [12]. All the systematic reviews used in analysis were for PTB high-risk groupsobesity, gestational diabetes, bacterial vaginosis, and so on, and starting period of administration was differrent in each study. Nordquvist et al. reported that probiotics intake from early pregnancy period reduced preterm birth, but probiotics intake from a late pregnancy period did not [10]. The target of this study is PTB low-risk women, and they took probiotics from before pregnancy period. So our study showed that probiotics intake from before the pregnancy period reduced the risk of early PTB (<34 weeks) in PTB low-risk women, but not reduce the risk for late PTB. Our study showed pre-conceptional fermented food intake might reduce early PTB $(<34$ weeks). This is new information. We may recommend taking fermented food before conception.

Our study has a few limitations. First, because the JECS is a cohort study and its data are based on self-administered questionnaires, the current study is subject to possible biases such as withdrawal bias, sampling bias (subjects may or may not have enrolled in the JECS project), selection bias (drop-out or withdrawal from the study), or recall bias (for questionnaires). For example, pregnant women who have high health awareness were expected to participate the JECS study, so it is possible that intake frequency of fermented foods may be higher than the truth by selection bias. Actually, PTB rate in this result, $3.0 \%$, is lower than commonly expected values. In addition, the first questionnaire asked about pre-pregnancy statement, but it was written after pregnancy. So that will not be appropriately reflected in the pre-pregnancy statement by recall bias. Second, the FFQ has not been validated for use with pregnant women. Furthermore, FFQs have several questions and may be a potential source of errors owing to participant assumptions, misunderstanding, or misreading of the questions. Furthermore, as different participants use different sizes of bowls and eat different types of soups, it may have been difficult to calculate and assess intake volumes for completing the FFQs. We therefore analyzed intake frequency, which is least affected by the above-mentioned biases.

\section{Conclusion}

We found an association between the dietary habits of pregnant women and early PTB ( $<34$ weeks), suggesting that for Japanese women with no risk factors for PTB, high consumption of miso soup, yogurt, and fermented soybeans before pregnancy may decrease their risk of early PTB (<34 weeks). Further studies are required to clarify lifestyle habits and environment factors that may govern dietary habits.

\section{Additional files}

Additional file 1: Table S1. Correlation for fermented foods intake frequency between in first questionnaire and second questionnaire. (DOCX $12 \mathrm{~kb}$ )

Additional file 2: Table S2. Correlation among fermented foods intake frequency and confounding factors in MT1. (DOCX 16 kb) 
Additional file 3: Table S3. Odds ratios (ORs) for relationships between preterm birth (PTB) risk and fermented food intake frequency after pregnancy by logistic regression analysis, (A)less than 34 weeks, (B) $34+0$ to $36+6$ weeks. (DOCX $17 \mathrm{~kb})$

\section{Abbreviations}

BMI: Body mass index; Cl: Confidence interval; FFQs: Food frequency questionnaires; FGR: Fetal growth restriction; GDM: Gestational diabetes mellitus; JECS: Japan Environment and Children's Study; OR: Odds ratio; PTB: Preterm birth

\section{Acknowledgements}

We are very grateful to all participants of JECS and to all members involved in the data collection. We would like to express our appreciation to all participants of this study and to all individuals involved in the data collection. The findings and conclusions of this article are solely the responsibility of the authors and do not represent the official views of the above government organizations.

Members of the JECS (principal investigator, Toshihiro Kawamoto) as of 2018: Yukihiro Ohya (National Center for Child Health and Development, Tokyo, Japan), Reiko Kishi (Hokkaido University, Sapporo, Japan), Nobuo Yaegash (Tohoku University, Sendai, Japan), Koichi Hashimoto (Fukushima Medical University, Fukushima, Japan), Chisato Mori (Chiba University, Chiba, Japan), Shuichi Ito (Yokohama City University, Yokohama, Japan), Zentaro Yamagata (University of Yamanashi, Chuo, Japan), Hidekuni Inadera (University of Toyama, Toyama, Japan), Michihiro Kamijima (Nagoya City University, Nagoya, Japan), Takeo Nakayama (Kyoto University, Kyoto, Japan), Hiroyasu Iso (Osaka University, Suita, Japan), Masayuki Shima (Hyogo College of Medicine, Nishinomiya, Japan), Yasuaki Hirooka (Tottori University, Yonago, Japan), Narufumi Suganuma (Kochi University, Nankoku, Japan), Koichi Kusuhara (University of Occupational and Environmental Health, Kitakyushu, Japan), and Takahiko Katoh (Kumamoto University, Kumamoto, Japan).

\section{Funding}

This study was funded by the Ministry of the Environment, Japan.

\section{Availability of data and materials}

The JECS database will not be shared publicly because of the ethics policy. For availability of data please contact jecs-en@nies.go.jp.

\section{Authors' contributions}

MI had full access to all data and takes responsibility for the integrity of the data and accuracy of the data analysis. MI, AT, and SS contributed to the study concept and design. The Japan Environment and Children's Study (JECS) Group contributed to the acquisition of data. MI, SY, and SS contributed to the drafting of the manuscript. MI, AT, ATsuchida, KM, AS, HO, $\mathrm{HI}$, and SS contributed to the critical revision of the manuscript for important intellectual content. AT, MI, KM, and $\mathrm{KH}$ contributed to the statistical analysis. The Japan Environment and Children's Study (JECS) Group obtained funding. ATsuchida, NY, KH, and HI contributed to the administrative, technical, or material support. All authors read and approved the final manuscript.

\section{Ethics approval and consent to participate}

The study protocol was reviewed and approved by the Ministry of the Environment's Institutional Review Board on Epidemiological Studies and by the Ethics Committee of all participating institutions. Written informed consent was obtained from all participating women and their partners.

\section{Consent for publication}

Not applicable.

\section{Competing interests}

The authors declare that they have no competing interests.

\section{Publisher's Note}

Springer Nature remains neutral with regard to jurisdictional claims in published maps and institutional affiliations.

\section{Author details}

Department of Obstetrics and Gynecology, Faculty of Medicine, University of Toyama, 2630 Sugitani, Toyama City, Toyama 930-0194, Japan. ${ }^{2}$ Clinical

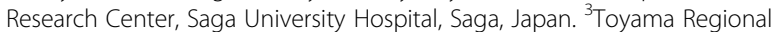
Center for JECS, University of Toyama, Toyama, Japan. ${ }^{4}$ Department of Public Health, Faculty of Medicine, University of Toyama, Toyama, Japan.

${ }^{5}$ Department of Biostatistics and Clinical Epidemiology, Graduate School of Medicine, University of Toyama, Toyama, Japan.

Received: 5 January 2019 Accepted: 11 April 2019

Published online: 01 May 2019

\section{References}

1. World Health Organization, Fact sheet No.363 - preterm birth. 2017 [cited April. 2019]. Available from: http://www.who.int/mediacentre/factsheets/ fs363/en/.

2. Behrman RE, Butler AS. Preterm birth: causes, consequences, and prevention. Washington, DC: National Academies Press; 2007.

3. Morken NH, Kallen K, Jacobsson B. Outcomes of preterm children according to type of delivery onset: a nationwide population-based study. Paediatr Perinat Epidemiol. 2007;21:458-64.

4. Lindstrom K, Winbladh B, Haglund B, Hjern A. Preterm infants as young adults: a Swedish national cohort study. Pediatrics. 2007;120:70-7.

5. Englund-Ogge L, Birgisdottir BE, Sengpiel V, Brantsaeter AL, Haugen M, Myhre R, et al. Meal frequency patterns and glycemic properties of maternal diet in relation to preterm delivery: results from a large prospective cohort study. PLoS One. 2017;12:e0172896.

6. Grieger JA, Grzeskowiak LE, Clifton VL. Preconception dietary patterns in human pregnancies are associated with preterm delivery. J Nutr. 2014;144: 1075-80.

7. Rasmussen MA, Maslova E, Halldorsson TI, Olsen SF. Characterization of dietary patterns in the Danish national birth cohort in relation to preterm birth. PLoS One. 2014;9:e93644.

8. Shiozaki A, Yoneda S, Yoneda N, Yonezawa R, Matsubayashi T, Seo G, et al. Intestinal microbiota is different in women with preterm birth: results from terminal restriction fragment length polymorphism analysis. PLoS One. 2014;9:e111374.

9. Myhre R, Brantsaeter AL, Myking S, Gjessing HK, Sengpiel V, Meltzer HM, et al. Intake of probiotic food and risk of spontaneous preterm delivery. Am J Clin Nutr. 2011;93:151-7.

10. Nordqvist M, Jacobsson B, Brantsaeter AL, Myhre R, Nilsson S, Sengpiel V. Timing of probiotic milk consumption during pregnancy and effects on the incidence of preeclampsia and preterm delivery: a prospective observational cohort study in Norway. BMJ Open. 2018;8:e018021.

11. Kriss JL, Ramakrishnan U, Beauregard JL, Phadke VK, Stein AD, Rivera JA, et al. Yogurt consumption during pregnancy and preterm delivery in Mexican women: a prospective analysis of interaction with maternal overweight status. Matern Child Nutr. 2018;14:e12522.

12. Jarde A, Lewis-Mikhael AM, Moayyedi P, Stearns JC, Collins SM, Beyene J, et al. Pregnancy outcomes in women taking probiotics or prebiotics: a systematic review and meta-analysis. BMC pregnancy childb. 2018;18:14

13. Tsai YT, Cheng PC, Pan TM. The immunomodulatory effects of lactic acid bacteria for improving immune functions and benefits. Appl Microbiol Biotechnol. 2012;96:853-62.

14. Marco ML, Heeney D, Binda S, Cifelli CJ, Cotter PD, Foligne B, et al. Health benefits of fermented foods: microbiota and beyond. Curr Opin Biotechnol. 2017:44:94-102.

15. Kawamoto T, Nitta H, Murata K, Toda E, Tsukamoto N, Hasegawa M, et al. Rationale and study design of the Japan environment and children's study (JECS). BMC Public Health. 2014;14:25.

16. Michikawa T, Nitta H, Nakayama SF, Ono M, Yonemoto J, Tamura K, et al. The Japan environment and Children's study (JECS): a preliminary report on selected characteristics of approximately 10000 pregnant women recruited during the first year of the study. J Epidemiol. 2015;25:452-8.

17. Yokoyama Y, Takachi R, Ishihara J, Ishii Y, Sasazuki S, Sawada N, et al. Validity of short and long self-administered food frequency questionnaires in ranking dietary intake in middle-aged and elderly Japanese in the Japan public health center-based prospective study for the Next generation (JPHC-NEXT) protocol area. J Epidemiol. 2016;26:420-32. 
18. Saurel-Cubizolles MJ, Zeitlin J, Lelong N, Papiernik E, Di Renzo GC, Breart G, et al. Employment, working conditions, and preterm birth: results from the Europop case-control survey. J Epidemiol Community Health. 2004;58:395-401.

19. Goldenberg RL, Culhane JF, lams JD, Romero R. Epidemiology and causes of preterm birth. Lancet. 2008;371:75-84.

20. Shiozaki A, Yoneda S, Nakabayashi M, Takeda Y, Takeda S, Sugimura M, et al. Multiple pregnancy, short cervix, part-time worker, steroid use, low educational level and male fetus are risk factors for preterm birth in Japan: a multicenter, prospective study. J Obstet Gynaecol Res. 2014;40:53-61.

21. Kishi R, Araki A, Minatoya M, Hanaoka T, Miyashita C, Itoh S, et al. The Hokkaido birth cohort study on environment and Children's health: cohort profile-updated 2017. Environ Health Prev Med. 2017;22:46.

22. Nakai K, Suzuki K, Oka T, Murata K, Sakamoto M, Okamura K, et al. The Tohoku study of child development: a cohort study of effects of perinatal exposures to methylmercury and environmentally persistent organic pollutants on neurobehavioral development in Japanese children. Tohoku J Exp Med. 2004;202:227-37.

23. Kotani Y, Shinkai S, Okamatsu H, Toba M, Ogawa K, Yoshida H, et al. Oral intake of Lactobacillus pentosus strain b240 accelerates salivary immunoglobulin a secretion in the elderly: a randomized, placebocontrolled, double-blind trial. Immun Ageing. 2010;7:11.

24. Lightfoot YL, Mohamadzadeh M. Tailoring gut immune responses with lipoteichoic acid-deficient Lactobacillus acidophilus. Front Immunol. 2013;4:25.

25. Atarashi K, Tanoue T, Shima T, Imaoka A, Kuwahara T, Momose Y, et al. Induction of colonic regulatory T cells by indigenous Clostridium species. Science (New York, NY). 2011;331:337-41.

26. Terada A, Yamamoto M, Yoshimura E. Effect of the fermented soybean product "Natto" on the composition and metabolic activity of the human fecal flora. Jpn J Food Microbiol. 1999;16:221-30.

27. Suzutani T, Nishiyama K, Hashimoto H. Effect of miso-soup on intestinal flora and immunity in mouse. Rep Cent Miso Res Inst. 2014:113-8.

28. Hendler I, Goldenberg RL, Mercer BM, lams JD, Meis PJ, Moawad AH, et al. The preterm prediction study: association between maternal body mass index and spontaneous and indicated preterm birth. Am J Obstet Gynecol. 2005;192:882-6.

29. Othman M, Neilson JP, Alfirevic Z. Probiotics for preventing preterm labour. Cochrane database Syst rev. 2007:24:Cd005941.

30. Ministry of Internal Affairs and Communications. The Family Income and Expenditure Survey http://www.stat.go.jp/data/kakei/index.html (2016) [cited April. 2019].

31. O'Mahony L, McCarthy J, Kelly P, Hurley G, Luo F, Chen K, et al. Lactobacillus and bifidobacterium in irritable bowel syndrome: symptom responses and relationship to cytokine profiles. Gastroenterology. 2005;128:541-51.

32. van Nood E, Vrieze A, Nieuwdorp M, Fuentes S, Zoetendal EG, de Vos WM, et al. Duodenal infusion of donor feces for recurrent Clostridium difficile. N Engl J Med. 2013;368:407-15.

33. Powers CE, MCShane DB, Gilligan PH, Burkhart CN, Morrell DS. Microbiome and pediatric atopic dermatitis. J Dermatol. 2015:42:1137-42.

34. Andreasen AS, Larsen N, Pedersen-Skovsgaard T, Berg RM, Moller K, Svendsen KD, et al. Effects of Lactobacillus acidophilus NCFM on insulin sensitivity and the systemic inflammatory response in human subjects. Br J Nutr. 2010;104:1831-8

35. Wang Y, Li X, Ge T, Xiao Y, Liao Y, Cui Y, et al. Probiotics for prevention and treatment of respiratory tract infections in children: a systematic review and meta-analysis of randomized controlled trials. Medicine. 2016;95:e4509.

Ready to submit your research? Choose BMC and benefit from:

- fast, convenient online submission

- thorough peer review by experienced researchers in your field

- rapid publication on acceptance

- support for research data, including large and complex data types

- gold Open Access which fosters wider collaboration and increased citations

- maximum visibility for your research: over $100 \mathrm{M}$ website views per year

At BMC, research is always in progress.

Learn more biomedcentral.com/submissions 